\title{
Análise da produção científica em tecnologia da informação: Estudo panorâmico dos artigos publicados pelos professores de biblioteconomia da UnB
}

\author{
Bruna Guedes Martins da Silva \\ Márcio Bezerra Da Silva \\ Universidad de Brasília - UnB, Brasil
}

ANALYSIS

\begin{abstract}
Resumo
Objetivo. O estudo analisa a produção científica em tecnologia da informação pelos professores do curso de biblioteconomia, da Faculdade de Ciência da Informação, da Univeridade de Brasília (Brasil), por meio dos Currículos da Plataforma Lattes dos citados professores.

Método. Adota o método indutivo, a pesquisa bibliográfica como técnica, pesquisa quantitativa como abordagem de coleta de dados e a análise documental a partir do Currículo Lattes (Plataforma Lattes) dos professores selecionados.

Resultados. Apresenta as áreas bases de dados, bibliotecas e repositórios digitais como as que possuem maior produção, e as áreas metadados e sistema de automação de bibliotecas como aquelas com carência de trabalhos publicados; os tipos de registros mais utilizados são os anais de congresso, trabalhos de conclusão de curso e artigos de periódicos, e os pouco usados são as teses e resumos expandidos; além da identificação de outras áreas não elencadas no escopo inicial do trabalho tais como gerenciamento eletrônico de documentos, preservação digital, segurança da informação, arquitetura da informação, hipertexto e tecnologias aplicadas.

Conclusões. A análise da produção científica auxilia na tomada de decisão, idealiza um panorama de pesquisa dos professores, ajuda a compreender como determinada área se comporta e sua principal composição de assuntos.
\end{abstract}

Palavras-chave

Produção científica ; Tecnologia da informação ; Biblioteconomia ; Currículo Lattes ; Universidade de Brasília ; Brasil

Analysis of scientific production in information technology: A panoramic study of articles published by librarianship professors from the UnB

\begin{abstract}
Objective. Research that objective to analyze the scientific production in information technology by professors of biblioteconomy, Faculty of Information Science, University of Brasilia (Brazil), through the Curriculum Lattes Platform of teachers cited.

Method. Adopts inductive method, bibliographical research and technical, quantitative research and data collection approach and document analysis from Lattes (Lattes Platform) of the selected teachers.

Results. Presents that the areas databases, libraries and digital repositories as that have the greatest production, metadata and library automation system areas as those with lack of jobs published, the most used types of records are the proceedings of congress, course conclusion papers and journal articles, as well the thesis and extended abstracts are little used, besides identifying other areas not listed in the original scope of work such as electronic document management, digital preservation, information security, information architecture, hypertext and applied technologies.

Conclusions. The analysis of scientific production helps in decision-making, idealizes an overview of professors' research, and helps understand how certain area behaves and its main composition of subjects.
\end{abstract}

Keywords

Scientific production ; Information technology ; Librarianship ; Currículo Lattes ; Universidade de Brasília ; Brazil 


\section{Introdução}

A Tecnologia da Informação (TI) está cada vez mais interligada à biblioteconomia, inserindo as unidades de informação, como a biblioteca, em um contexto virtual com fins de facilitar a interatividade com o usuário na busca pela informação e sua recuperação, independente da localização física. Para acompanhar esse percurso e consequente mudança na formação profissional, a literatura científica se apresenta como subsidiária às discussões que permeiam a TI, onde a universidade se torna um lugar propício para que estudos e pesquisas sejam desenvolvidas. Para tanto mostra-se necessário o empenho dos pesquisadores para indicar quais tecnologias são mais adequadas para uma determinada realidade como, por exemplo, adequação de disciplinas quanto aos recentes adventos e aquisição (melhoria) de parques tecnológicos.

Dando ênfase sobre a participação da universidade nesse processo científico, Merlo (2006) defende que esta deve ser apresentada como a principal organização de geração e mediação de conhecimento e responsável pela consolidação de um ambiente democrático e de livre produção e reflexão sobre os aspectos sociais.

O contexto supracitado é a realidade vivida pelo curso de biblioteconomia da Faculdade de Ciência da Informação ( $\mathrm{FCl}$ ), da Universidade de Brasília (UnB - Brasil), formalizada pelo momento de transição no corpo docente com a chegada de novos professores, que por sua vez assuntos passarem a ser abordados, assim como outros tornaram-se defasados. A presente percepção se deu a partir de leituras de artigos científicos, livros, anais de congresso e outros materiais didáticos apresentadas ao longo do curso, ou seja, produções em $\mathrm{TI}$ apresentadas no ensino, nos permitindo delinear, inicialmente, a TI em biblioteconomia conforme as seguintes áreas: bases (banco) de dados; biblioteca e repositório digital; revistas eletrônicas; metadados; sistema de automação de bibliotecas (SAB); além dos recursos e aplicações da Web.

$\mathrm{Na}$ tentativa de descobrir outras áreas de TI aplicadas à biblioteconomia, como também o atual status da produção científica em TI, justificando assim a realização do presente estudo, problemas de pesquisa (problematização) surgiram ao levarmos este contexto à realidade do curso de biblioteconomia da UNB, a saber: Quais são as áreas que compõe TI em biblioteconomia na FCI/UNB? O que tem sido produzido pelos professores do curso de biblioteconomia da FCI/UNB na área de TI? Quais áreas possuem as maiores e menores quantidades de produção científica em TI?

Para responder as problematizações desta pesquisa, frente a nossa compreensão preliminar sobre $\mathrm{TI}$ em biblioteconomia, objetivamos, de forma geral, analisar a produção científica em TI dos professores do curso de biblioteconomia da FCl/UnB e, de maneira específica, identificar a produção científica dos professores de biblioteconomia da UnB na área de TI, mensurar os tipos de registro da produção científica em TI e descobrir quais áreas em TI possuem maiores e menores quantidades de produção cientifica.

\section{Produção científica: apontamentos históricos e conceituais}

O tema produção científica tem seu surgimento atrelado ao da ciência. Ao passo do desenvolvimento da ciência, surgiram meios para produção de novos conhecimentos e posterior disseminação, por vezes, apresentando-se como tendências de uma área com base no momento histórico, contexto social, político e econômico. De acordo com Meadows (1999, p.1), para examinarmos tais tendências é necessário entender "a natureza do meio empregado para transmitir informações e as necessidades dos membros da comunidade científica, tanto produtores quanto receptores da informação".

No contexto histórico da produção científica destaca-se a impressa de Gutemberg. Segundo Valério (2012, p.157), a partir da citada tecnologia, "[...] percebemos que a circulação e disseminação de informação ficaram mais fáceis". Neste momento, é possível observar o ganho de espaço da produção científica por causa da necessidade que é apresentada pelos indivíduos para obtenção de conhecimento. Com o tempo, recebendo resquícios da evolução da impressa, o importante papel das universidades já pode ser observado. De acordo com Meadows (1999, p. 4), "[...] algumas delas ficaram responsáveis por cuidar dos trabalhos de impressão e editoração de livros [...]", fazendo com que o conhecimento gerado assumisse um cunho mais científico. Ainda segundo o autor, outro marco relevante para produção científica foi a criação das revistas científicas. O primeiro passo para sua origem ocorreu com o surgimento das sociedades, como a Royal Society. Elas eram constituídas por indivíduos que se reuniam para debater questões filosóficas. Como eles mantinham contato com membros estrangeiros, surgiu a necessidade de criação de um meio para se comunicarem, e a carta foi o meio escolhido (MEADOWS, 1999). 
A produção científica deflagra-se de fato especialmente a partir da Segunda Guerra Mundial, quando alguns países menores da época, como Japão e União das Repúblicas Socialistas Soviéticas (URSS), começaram a aumentar o investimento no campo da pesquisa. Segundo Price (1976), países maiores como Estados Unidos da América (EUA) também investiram mais, porém, como os recursos aplicados já eram altos, não causou tanto impacto como os dos países menores.

Para Santos (2003), na Segunda Guerra Mundial, os pesquisados em países cientificamente avançados ficaram responsáveis por decidir acerca de assuntos relacionados com Ciência e Tecnologia (C\&T), graças à comprovação de sucesso na área de energia nuclear. No entanto, com o aparecimento de novos desafios, esse papel não foi desempenhado de forma deseja pelos cientistas, exigindo dos mesmos soluções, proposições e validações de indicadores, apresentando seus alcances e limitações, com fins de identificar tendências em C\&T. Assim, os pesquisadores voltaram a se destacar por causa de suas atividades desenvolvidas como propor e validar os indicadores, equacionar problemas científicos e desenvolver soluções. Nesse contexto, surge a "Cienciometria", campo que tem como objetivo principal gerar informações e discussões que contribuam para a superação dos desafios característicos da ciência moderna. O conceito de "Cienciometria" tem ligação com a produção científica, já que é um indicador para geração de conhecimento. Além disso, influenciou o surgimento de medidas Bibliométricas, ferramentas importantes para mapear, analisar e quantificar a produção científica de determinada área, apresentando como ferramentas mais conhecidas as Leis de Lotka, Bradford e Zipf.

No Brasil, a criação da primeira universidade, a revolução de 1930 e o impulso na industrialização foram fatores importantes para o desenvolvimento da pesquisa científica no país e também para sua consolidação, construindo um campo, de produção científica, que abrange artigos de periódicos, livros e seus capítulos, projetos de pesquisa, trabalhos publicados em anais de congresso e apresentações.

A produção científica pode ser definida como o "volume de documentos gerados, onde se encontram registradas e disseminadas descobertas numa área da ciência” (CUNHA; CAVALCANTI, 2008, p. 294). Metodologia científica também é "[...] conhecida como produção intelectual, produção acadêmica, produção do conhecimento, expressões essas que abarcam as produções bibliográficas, técnica e artísticas realizadas por determinada comunidade" (NORONHA; KIYOTANI; JUANES, 2003, p. 140). Esta produção possui importância na tomada de decisões no âmbito acadêmico. Por esse motivo, trata-se de um processo na comunicação científica, certame que "diz respeito à transferência de informações científicas, tecnológicas ou associadas a inovação e que se destinam aos especialistas em determinada área de conhecimento" (BUENO, 2010, p. 2).

Com base em Weitzel (2006, p. 88), "a comunicação científica pode ser entendida como um processo que envolve a construção, comunicação e uso do conhecimento para possibilitar a promoção de sua evolução". Ela possui dois modelos, o primeiro chamado de clássico, que tem como foco a geração e a comunicação da informação produzida; e o segundo rotulado de modelo atual, que traz conceitos como Open Access (OA), por isso o enfoque se encontra no acesso e uso da informação, ligado a utilização das TI, como e-mail, lista de discussão virtual, consultas online (WEITZEL, 2006), além de repositórios institucionais, bibliotecas digitais e base de dados.

É possível notar que ambos os modelos de comunicação estão ligados à produção científica, no entanto, conforme Mueller (2000), para que seja considerada como tal é necessário que esta produção esteja baseada em alguma metodologia científica e também ser avaliado por profissionais do âmbito, a fim de proporcionar maior confiabilidade ao conhecimento gerado. De acordo com Marconi (2003, p. 112), a metodologia científica "engloba métodos de abordagem e de procedimentos e técnicas". Já com base em Prodanov (2013, p. 14), ela é uma "disciplina que consiste em estudar, compreender e avaliar os vários métodos disponíveis para realização de uma pesquisa acadêmica".

De posse dos documentos produzidos, com base em Perucchi (2012), é possível citar a quantidade de trabalhos publicados e apresentados em eventos, já que a partir deste momento será possível observar quanto que determinada área está crescendo. Neste sentido, diversos pesquisadores escrevem artigos com o intuito de verificar, analisar e quantificar a produção científica em determinada área, como na ciência da informação $(\mathrm{Cl})$. Para exemplificar, pode-se citar o Encontro Nacional de Pesquisa em Ciência da Informação $\left(\right.$ ENANCIB) ${ }^{1}$, considerado o maior evento da área de $\mathrm{Cl}$ e que possui um grupo de trabalho (GT) que discute a produção científica nacional e internacional, intitulado GT7 - Produção e Comunicação da Informação em Ciência, Tecnologia e Inovação (CT\&l). Também vale destacar os programas de Mestrado e Doutorado enquanto instâncias responsáveis pela formação de pesquisadores, que por sua vez apresentam a produção de teses e dissertações como frutos de seus estudos. No âmbito da graduação existem projetos de estímulo à formação de 
novos pesquisadores, despertando o interesse dos estudantes pela ciência, como o Programa Institucional de Bolsas de Iniciação Científica (PIBIC) ${ }^{2}$. Mas, independente do nível acadêmico, conforme Noronha (2003), conhecer a produção científica de um determinado campo é determinar as principais tendências de temas e metodologias, além das áreas específicas mais abordadas nos trabalhos científicos.

De forma ampla, a universidade deve proporcionar um ambiente que facilite o crescimento de pesquisadores, constatação que se amplia a partir dos recentes adventos da TI, que permitiu o aumento na produção de informação, bem como incidiu no desenvolvimento de recursos para o respetivo tratamento, organização, recuperação, dissseminaçnto e mensuração com fins de tomada de decisão.

\section{Tecnologia da informação: uma simples compreensão}

Com o aumento das pesquisas se tornou necessário uma organização do conhecimento produzido. Foi então que começou a se buscar meios e alternativas para a organização dessa informação de modo que a recuperação fosse realizada de forma eficiente e eficaz. Neste momento deflagra-se o uso de recursos oriundos da TI. Enquadra-se aqui, de longa data, o uso de computadores que ajudaram na construção de modelos de produção, tratamento, busca e recuperação de informação. Segundo Meadows (1999), na década de 1960, os primeiros computadores foram vistos com um grande potencial para auxiliar no processamento das informações bibliográficas. O método utilizado inicialmente para busca de informações era a atribuição de palavras-chaves. Elas são termos escolhidos para representar o conteúdo temático de um documento. Isso poupava o tempo do bibliotecário e também do usuário.

O usuário pôde interagir, mais intimamente e de forma facilitada, com os recursos informacionais, graças aos adventos da TI, conjunto tecnológico definido por Cunha e Cavalcanti (2008, p. 356) da seguinte maneira:

Tecnologia baseada na eletrônica e dirigida ao tratamento da informação, compreendendo toda a tecnologia informática e das telecomunicações, juntamente com partes da eletrônica de consumo e radiodifusão. Suas aplicações são industriais, comerciais, administrativas, educativas, médicas, científicas, profissionais e domésticas.

TI pode ser definida como o conjunto de atividades e soluções providas por recursos computacionais que visam permitir a obtenção, o armazenamento, o acesso, o gerenciamento e o uso das informações (ALECRIM, 2011). A visão do autor corrobora com nossa compreensão inicial sobre áreas que formam a TI em biblioteconomia anteriormente citadas: bases (banco) de dados; biblioteca e repositório digital; revistas eletrônicas; metadados; $\mathrm{SAB}$; além dos recursos e aplicações da Web.

As bases de dados, enquanto instrumentos da TI responsáveis pelo armazenamento, tratamento e organização de informações, tem como principal finalidade, segundo Vilan Filho (2010), controlar coleções de itens. Segundo Rowley (2002, p. 125), base de dados é definida como "uma coleção geral e integrada de dados junto com a descrição deles, gerenciada de forma a atender a diferentes necessidades de seus usuários”. Cunha (1989, p. 45) defende que as bases de dados "são fontes de informação computadorizadas que podem ser pesquisadas num modo interativo ou conversacional através de um terminal de computador, telex ou mesmo um microcomputador". Como exemplos citamos a Scientific Electronic Library Online (SciELO) ${ }^{3}$, uma base de dados de artigos, fascículos e periódicos, e integrante de um projeto capitaneado pela Fundação de Amparo à Pesquisa do Estado de São Paulo (FAPESP), Biblioteca Regional de Medicina (BIREME) e Centro Nacional de Desenvolvimento Científico e Tecnológico (CNPQ).

A biblioteca digital, segundo Cunha (2008), é um ambiente que combina estrutura e coleta de informação, atividades básicas em bibliotecas e arquivos, com a utilização da representação digital da informação. Por sua vez, Silva (2011, p. 20), define biblioteca digital da seguinte maneira:

[...] conjunto de objetos digitais construídos a partir do uso de instrumentos eletrônicos, concebidos com o objetivo de registrar e comunicar pensamentos, ideias, imagens e sons disponíveis a um contingente ilimitado de pessoas, dispersas onde quer que a plataforma world wide alcance.

Como exemplo, é possível apresentar a Biblioteca Digital Brasileira de Teses e Dissertações (BDTD). Ela reúne teses e dissertações das Instituições de Ensino Superior (IES) com as quais o Instituto Brasileiro de Ciência e Tecnologia (IBICT) possui parceria. Através desse projeto, a BDTD do IBICT estimula a publicação de trabalhos de pós-graduação em meio eletrônico. 
No caso do repositório digital, pode ser considerado um meio de disseminação da informação científica e tem sido usado por instituições, órgãos públicos e empresas para promover o acesso às suas produções acadêmicas e/ou profissionais. Conforme Viana, Márdero Arellano e Shintaku (2005, p. 3), "[...] é uma forma de armazenamento de objetos digitais que tem a capacidade de manter e gerenciar material por longos períodos de tempo e prover o acesso apropriado". Leite (2009, p. 19, grifo do autor) assim complementa a discussão:
A expressão 'repositórios digitais', no contexto do acesso aberto, é empregada para denominar os vários tipos de aplicações de provedores de dados que são destinados ao gerenciamento de informação científica, constituindo-se, necessariamente, em vias alternativas de comunicação científica.

Conforme podemos observar, Leite (2009, p. 15) cria uma linha tênue entre o conceito de repositório digital com a Iniciativa de Acesso (arquivo) Aberto - Open Archives Initiative (OAI):

\begin{abstract}
O acesso aberto nesse contexto significa a disponibilização livre pública na Internet, de forma a permitir a qualquer usuário a leitura, download, cópia, distribuição, impressão, busca ou criação de links para os textos completos dos artigos, bem como capturá-los para indexação ou utilizá-los para qualquer outro propósito legal.
\end{abstract}

Dentre alguns exemplos de repositórios institucionais, citamos o Repositório Institucional $(\mathrm{RI})^{4}$ da UnB, que visa reunir a produção dos pesquisadores da universidade, tais como artigos de periódicos, livros, capítulos de livros entres outras publicações, desde que os seus editores autorizem o arquivamento desses trabalhos no espaço digital em questão. Além disso, as teses e dissertações produzidas na UnB são disponibilizadas neste repositório também.

Quanto as revistas eletrônicas, tecnologia que pode ser considerada como área da TI em biblioteconomia devido aos recursos de software envolvidos, devemos mencionar os periódicos científicos, aos quais, de acordo com Mueller (2000, p. 73), "[...] surgiram no século XVII na Europa [...] [impulsionados] por uma grande mudança que ocorreu na época, pois a comunidade científica começou a exigir, dos cientistas, comprovações baseadas em observação e experiência empírica [...]".

O periódico é um meio muito utilizado para divulgar as novidades de uma determinada área por meio de uma publicação ágil se comparada com o trâmite publicitário dos livros. Neste sentido, para facilitar o fluxo de informação dos periódicos são usados alguns recursos digitais, promovendo, desta forma, as revistas eletrônicas. Para tanto, se faz necessário a adoção de recursos de software, como o Sistema Eletrônico de Editoração de Revistas (SEER).

O SEER faz parte da nova geração de sistemas de gerenciamento de periódicos científicos e, no Brasil, ele surge como modelo alternativo de publicação do conhecimento científico para ampliar o acesso, a preservação e o impacto das pesquisas e dos resultados daí provenientes (MÁRDERO ARELLANO; SANTOS; FONSECA, 2005, p. 77).

De acordo com o manual do SEER, disponibilizado no site do IBICT (2006, p. 9), são cinco principais as etapas do processo:

Fila de Submissões: Itens iniciam aqui, sendo designados a um editor; Avaliação da Submissão: Itens passam pela avaliação por pares cega e avaliação editorial; Edição da Submissão: Itens recebem edição de texto, composição e leitura de provas; Fila de Agendamento: Itens são designados a uma edição e/ou volume; Sumário: Itens são ordenados e a edição é publicada.

Um exemplo de revista eletrônica, que faz parte do SEER, é a Revista Ibero-Americana de Ciência da Informação $(\mathrm{RICl})^{5}$. É um periódico semestral editado pela $\mathrm{FCl} / U n \mathrm{nB}$ por meio do programa de pós-graduação, com enfoque em temáticas da $\mathrm{Cl}$ e áreas afins.

As bibliotecas e repositórios digitais, além das revistas eletrônicas, disponibilizam seus materiais segundo as recomendações da OAI. Para Ferreira, Modesto e Weitzel (2004), essa iniciativa foi criada com o objetivo de desenvolver e promover normas de interoperabilidade a fim de facilitar a disseminação eficiente de informações na Internet. Salientamos que o termo "arquivo aberto" foi consolidado por meio da Convenção de Santa Fé no México em 1999.

Metadados é outra área que foi considerada como campo da TI em biblioteconomia. Estes atuam como auxiliadores no processo de representação, mais especificamente, na descrição de informações disponíveis em um sistema digital. De acordo com Souza, Catarino, Santos (1997, p. 93) "são descrições de dados 
armazenados em banco de dados". Ainda segundo os autores, para cada tipo de necessidade existe um padrão de metadados que melhor atende determinada situação, ou seja, "[...] a finalidade principal dos metadados é documentar e organizar de forma estruturada os dados das organizações com o objetivo de minimizar duplicação de esforços e facilitar a manutenção dos dados" (SOUZA; CATARINO; SANTOS, 1997, p. 94). Segundo Da Silva (2013), os principais tipos de metadados são:

Descritivo: busca a descoberta e identificação de informação, por exemplo, [...] Dublin Core; Estrutural: indicam como objetos compostos são agrupados/ligados no ambiente/website (hyperlink); Administrativo: informações para ajudar a gerenciar o recurso, preservação digital, direitos de acesso, processo de digitalização, aquisição etc.; Técnico: aspectos técnicos do documento, compressão, resolução, arquivo, formato etc.

Um exemplo de padrão de metadados é o Dublin Core. Este formato, segundo Souza, Vendrusculo e Melo (2000, p. 93) "pode ser definido como sendo o conjunto de elementos de metadados planejado para facilitar a descrição de recursos eletrônicos". O padrão Dublin Core é constituído de um esquema composto por 15 campos (atributos), a saber: identificador, colaborador, cobertura, criador, data, descrição, formato, linguagem, publicador, relação, direitos, fonte, assunto, título e tipo de recurso.

Os SAB também representam uma área de TI em biblioteconomia, que tem a função de gerenciar as atividades e serviços oferecidos pelas bibliotecas a partir de recursos de software. Em suma, ações como o registro das informações e controle de empréstimo passam a ocorrer mediante uso de um programa de computador. Podemos dizer que automatizar uma biblioteca "[...] objetiva colocar ao alcance do usuário uma base de dados com informações internas de documentos e materiais bibliográficos gerados ou adquiridos pela empresa, de forma a facilitar seu acesso" (REZENDE, 2000, p. 56). Dois são os tipos de licença para os SAB, sendo um chamado de proprietário, ou seja, tipo de software que se faz necessário pagar uma licença de uso. Esta licença varia de acordo com o tempo da sua assinatura e com os módulos adquiridos como o de classificação, de catalogação, e assim se equivale a todos os serviços existentes na biblioteca (DA SILVA, DIAS, 2010, p. 9), exemplificado pelo Pergamum ${ }^{6}$ : sistema integrado de bibliotecas. A outra licença é denominada de livre. Conforme Da Silva e Dias (2010, p. 10), "a utilização de softwares baseados no paradigma de liberdade de uso tem sido cada vez maior. Alguns permitem apenas o seu uso e outros [...] também permitem sua comercialização e alterações no seu código fonte", ou seja, software freeware (gratuitos) e código-fonte aberto (open source) ou livres. Staliman (1999, p. 56), um dos maiores defensores e estudiosos de software livre afirma que:
É aquele que se refere à liberdade dos usuários ao executarem, copiarem, distribuírem, estudarem, modificarem e aperfeiçoarem o mesmo. Mais precisamente, ele se refere a quatro tipos de liberdade: a liberdade de executar o programa, para qualquer propósito; a liberdade de estudar como o programa funciona e adaptá-lo para as suas necessidades (acesso ao código-fonte é um pré-requisito para esta liberdade); a liberdade de redistribuir cópias de modo que você possa ajudar ao seu próximo; a liberdade de aperfeiçoar o programa e liberar os seus aperfeiçoamentos, de modo que toda a comunidade se beneficie, sendo o acesso ao código-fonte é um pré-requisito para esta liberdade.

Um exemplo de SAB livre é o Biblivre ${ }^{7}$, um dos mais difundidos atualmente no Brasil e que conta com o apoio do Banco Itaú, Fundação Biblioteca Nacional (FBN) e Ministério da Cultura. Este software vem chamando atenção dos bibliotecários pela sua simplicidade, liberdade de uso, como também pela possibilidade de alterar o seu código fonte.

Por fim invocamos a Web. Presente na Internet, a Web possui três gerações, a primeira chamada de Web 1.0 (top dow - de cima para baixo), na qual, o espaço era pouco interativo, ou seja, propício apenas para leitura e consumo sem interação. De acordo com Da Silva (2013a), a Web 1.0 surgiu a partir da proposta de criação de um sistema de hipertexto que visava o compartilhamento de informação em rede, cunhado por Tim Berners-Lee. Esta iniciativa resultou em ferramentas necessárias para o desenvolvimento da World Wide Web (WWW) que são: o protocolo Hyper Text Transfer Protocol (HTTP), a linguagem Hyper Text Markup Language (HTML) e o primeiro navegador Web e editor, chamado inicialmente de WYSIWYG ${ }^{8}$ e depois NEXUS.

O segundo estágio é denominado Web 2.0, geração que permite maior interação do usuário com o ambiente virtual. A partir de sua criação é possível colaborar, interagir e modificar alguns recursos da Web. Com base em Da Silva (2013b), ela nasceu para determinar o segundo estágio de geração de serviços e comunidades, tendo como idealizadora a empresa norte americana O'Reilly Media ${ }^{9}$, em 2004. É a "mudança para uma Internet plataforma, onde o objetivo é desenvolver aplicativos que aproveitem a inteligência coletiva em rede" (O'REILLY, 
2005, p. 2). Ainda segundo o autor, na Web 2.0, "o serviço fica automaticamente melhor quanto mais pessoas usam" (O`REILLY, 2005, p. 2). Com base em ANDRADE et al. (2011), podemos assim defini-la:

Web 2.0 é um termo que descreve a tendência no uso da World Wide Web, onde as tecnologias e aplicações são projetadas com o objetivo de realçar a criatividade, a informação compartilhada, e, sobretudo, a colaboração entre usuários. De consumidor, o usuário passa ao papel de produtor de informação e conhecimento na Web 2.0.

Como exemplos de aplicações da Web 2.0 (button up - de baixo para cima), elecamos o Delicious, que permite o usuário guardar os links de Websites como favoritos, além de compartilhá-los; o Flickr, que é uma rede social que visa o compartilhamento e a organização de fotos, vídeos e outros instrumentos gráficos; o Really Simple Syndication (RSS), também comumente chamado de Feeds e que significa uma maneira simples de apresentar os conteúdos de um determinado Website, a partir do cadastro do usuário no ambiente, por meio de mensagens com uma pequena quantidade de caracteres (resumo); a Wikipédia, ambiente onde as pessoas podem escrever/contribuir/colaborar com o assunto/texto produzido; e as redes sociais digitais como o Facebook, aplicação que permite ao usuário criar seu perfil e, assim, promover o compartilhamento de informações, de acordo com suas preferências, o Twitter, espécie de microblog em que os usuários desse serviço recebem atualizações das pessoas de seu interesse (seguidores), como também criam textos de no máximo 140 caracteres; e o Google+, rede social concorrente do Facebook que utiliza recursos para permitir o compartilhamento de fotos, vídeos e utilização de chat (hongout), todos integrados aos serviços do Google e seu sistema operacional (SO) Android.

A Web 3.0 (Web Semantic - semântica) é a geração que objetiva implementação de recursos de software responsáveis pela filtragem de informações recuperadas. Para Ramalho, Vidotti e Fujita (2007), a Web 3.0 foi uma iniciativa do World Wide Web Consortium (W3C), em 2000, novamente encabeçada por Tim Berners-Lee após a escrita do seu livro intitulado Weaving the Web.

[A Web 3.0 é] uma série de camadas sobrepostas, onde cada camada ou tecnologia deveria obrigatoriamente ser complementar e compatível com as camadas inferiores, ao mesmo tempo em que não deveria depender das camadas superiores, possibilitando assim uma estrutura idealmente escalonável, que indicasse os passos e as tecnologias necessários para a concretização do projeto Web Semântica. (RAMALHO; VIDOTTI; FUJITA 2007)

De acordo com Sabino (2007, p. 1), a Web 3.0 "se baseia numa maior capacidade do software em interpretar os conteúdos em rede, devolvendo resultados mais [objetivos] e personalizados [...]". Enquanto a Web 1.0 está baseada na taxonomia e a Web 2.0 na folksonomia, a Web 3.0 está ligada à web semântica. Na terceira geração da Web, quem faz a filtragem das informações recuperadas são os computadores, através de recursos de software que funcionam como instrumentos de inteligência artificial. Como exemplo de ambiente que utiliza a Web semântica temos o Friend of a Friend (FOAF) ${ }^{10}$, iniciativa que visa desenvolver projetos em que a Web seja legível por máquina por meio da descrição de pessoas, as quais estarão ligadas umas com as outras (interligando redes sociais) quanto ao que produzem e contribuem na rede mundial de computadores.

\section{Metodologia}

O alcance dos objetivos se deram a partir de um percurso metodológico constituído por um campo de pesquisa centrado nos quatro professores que ministram disciplinas na área de TI entre os 17 que compõem o corpus acadêmico do curso de biblioteconomia da FCI/UnB. O meio utilizado para coleta de dados desse grupo foi o currículo dos correspondentes professores de TI cadastrados na Plataforma Lattes ${ }^{11}$ do Conselho Nacional de Desenvolvimento Científico e Tecnológico (CNPQ), ambiente escolhido pelo fato de desde 1999 representar "[...] a experiência do CNPq na integração de bases de dados de Currículos de Grupos de pesquisa e de Instituições em um único Sistema de Informações" (CNPQ, 2013). Conforme Lira Júnior (2009), é "um sistema que padroniza e disponibiliza os currículos dos envolvidos em pesquisa em todo o Brasil", sendo o "[...] único no mundo em sua obrigatoriedade e amplitude". Sua dimensão atual se estende não só às ações de planejamento, gestão e operacionalização do fomento do CNPq, mas também de outras agências de apoio federais e estaduais, das fundações estaduais de apoio à C\&T, das Instituições de Ensino Superior (IES) e dos institutos de pesquisa. Além disso se tornou estratégica para a formulação das políticas do Ministério de Ciência e Tecnologia (MCT) e de outros órgãos governamentais da área de Ciência, Tecnologia e Inovação (CT\&I). Neste sentido justificamos a escolha da Plataforma Lattes, já que trata-se de uma base acadêmica e oficial no país onde os professores e pesquisadores cadastram suas atuações, formações, produções e experiências, neste caso, referente aos docentes de TI do curso de biblioteconomia da FCI/UnB. 
No que se refere as características da pesquisa foram adotados o método indutivo, a pesquisa bibliográfica como técnica, pesquisa quantitativa como abordagem de coleta de dados e a análise documental. No entanto, para a referida coleta, vale salientar que foram escolhidos tipos documentais presentes no Currículo Lattes e que são adotados como objetos de avaliação do docente pela Coordenação de Aperfeiçoamento de Pessoal de Nível Superior (CAPES) ${ }^{12}$, ou seja, anais de congresso, artigos científicos, dissertações, livros, projetos de pesquisa, resumos expandidos, teses, trabalhos de conclusão de curso (TCC) e outros. Além disso, os documentos supracitados deveriam ser produzidos e/ou apresentados em revistas, ambientes digitas, congressos etc. de $\mathrm{Cl}$, biblioteconomia e áreas afins como arquivologia, museologia e ciência da computação (CC).

A pesquisa correspondeu a um espaço temporal iniciado em fevereiro de 2013 até outubro de 2014. Neste sentido, no primeiro semestre foi levantada a literatura básica para a compreensão dos assuntos abordados e formalização da coleta dos dados, que por sua vez ocorreu no segundo semestre de 2013. Quanto a análise, ocorreu em dois momentos: ainda no segundo semestre de 2013 mensuramos os tipos de produção científica conforme as áreas de TI em biblioteconomia pré-estabelecidas e no primeiro semestre de 2014 a análise direcionou-se a identificar outras áreas da TI em biblioteconomia não definidas inicialmente, bem como seus respectivos tipos de produção. No segundo semestre de 2014 o conteúdo do trabalho foi estruturado conforme a literatura levantada e chegou-se a proposta formal, ordenado por uma sequência iniciada na introdução com os problemas de pesquisa e objetivos; nas seções um e dois exibem-se a fundamentação teórica, especificamente sobre produção científica e TI; na seção três delineamos os aspectos metodológicos; na seção quatro são apresentados e comentados os resultados da pesquisa; e por fim, na seção cinco, são expostas as considerações finais.

\section{Analisando e interpretando os dados da pesquisa}

A análise bibliométrica dos registros da Base de dados LISA foi dividida em quatro partes:

1. distribuição de frequência relativa acumulada dos 153 títulos de periódicos;

2. dendograma dos descritores de maior frequência na temática Ergonomia;

3. distribuição temporal de frequência;

4. distribuição dos títulos de periódicos, análise bibliométrica dos 1750 artigos e das citações realizadas pelos autores na construção de seus respectivos artigos.

A partir das seguintes áreas de TI procurou-se, conforme nossa compreensão preliminar sobre o assunto, responder às indagações trazidas na presente pesquisa, a saber: bases (banco) de dados; biblioteca e repositório digital; revistas eletrônicas; metadados; sistema de automação de bibliotecas (SAB); além dos recursos e aplicações da Web. Deste modo foram separadas as quantidades de trabalhos produzidos pelos professores já mencionados e depois analisadas separadamente a fim de apresentar um panorama do que vem sendo produzindo cientificamente em TI, tanto quanto as áreas, como também os tipos de produção. Além disso, foi possível identificar outras áreas que não foram contempladas ao longo da fundamentação teórica do presente trabalho.

Do total de referências analisadas, no valor 1.362 produções, apenas 191 (14\%) correspondem aos materiais em áreas de TI, analisadas em duas partes: a primeira refere-se a delimitação inicial das áreas de $\mathrm{TI}$ e a segunda apresenta as outras áreas identificadas ao longo da coleta de dados.

\section{1 Área de TI em biblioteconomia}

Na tabela um (1) buscou-se identificar a produção científica nas áreas que foram consideradas como TI em biblioteconomia, resultando na maior parte da produção científica concentrada no assunto base de dados (24\%). Bibliotecas digitais também é um assunto recorrente nos trabalhos dos docentes de biblioteconomia, correspondendo a $22 \%$, enquanto que os metadados representam a menor quantidade de produção com apenas $1 \%$. 


\begin{tabular}{l|c|c}
\multicolumn{1}{c|}{ Areas } & Produção & Porcentagem \\
\hline Bases (banco) de dados & 47 & $24 \%$ \\
\hline Biblioteca digital & 42 & $22 \%$ \\
\hline Repositório digital & 38 & $20 \%$ \\
\hline Web & 29 & $15 \%$ \\
\hline Revista eletrônica & 26 & $14 \%$ \\
\hline SAB & 07 & $04 \%$ \\
\hline Metadados TOTAL & 02 & $01 \%$ \\
\hline \multicolumn{1}{c|}{ TOI } \\
\hline
\end{tabular}

Tabela 1 - Áreas de TI em biblioteconomia

$\mathrm{Na}$ tabela dois (2) se destacou a Web 2.0, provavelmente pelas atuais redes sociais na Internet e demais estudos quanto à representação, organização e recuperação de informação em Websites. Os usuários estão mais inseridos nesse ambiente virtual, já que os permite interagir e colaborar com os recursos que estão utilizando como o Facebook e Twitter, realidade que deve ser aplicada, de forma mais incisiva, nos ambientes de bibliotecas como, por exemplo, na referência virtual e nas redes sociais das próprias unidades de informação.

\begin{tabular}{c|c|c}
\hline \multicolumn{1}{c|}{ Areas } & Produção & Porcentagem \\
\hline Web 2.0 & 23 & $80 \%$ \\
\hline Web 3.0 & 05 & $17 \%$ \\
\hline Web 1.0 TOTAL & 01 & $03 \%$ \\
\hline
\end{tabular}

Tabela 2 - Áreas de TI em Web

Por sua vez, na tabela três (3), o objetivo foi identificar os tipos de registros da produção científica em $\mathrm{TI}$ conforme o Currículo Lattes de cada professor. O resultado nos mostrou que os anais (27\%) e os TCC (25\%) foram os registros mais produzidos nas áreas de TI, nos inferindo que as produções estão mais direcionadas à graduação. Por outro lado, os resumos expandidos representam apenas $1 \%$ do total de produções.

\begin{tabular}{|c|c|c|}
\hline Tipos de registro & Produção & Porcentagem \\
\hline Anais de congressos & 50 & $27 \%$ \\
\hline TCC & 47 & $25 \%$ \\
\hline Artigos & 37 & $19 \%$ \\
\hline Outros $^{13}$ & 16 & $08 \%$ \\
\hline Capítulos de Livros & 10 & $05 \%$ \\
\hline Dissertação & 10 & $05 \%$ \\
\hline Livros & 08 & $04 \%$ \\
\hline Projetos de pesquisa & 07 & $04 \%$ \\
\hline Tese & 04 & $02 \%$ \\
\hline Resumos expandidos & 02 & $01 \%$ \\
\hline $\begin{array}{r}\text { TOTAL } \\
\end{array}$ & 191 & $100 \%$ \\
\hline
\end{tabular}

Tabela 3 - Tipos de registro da produção científica em TI

Na sequência buscou-se descobrir os tipos de registros da produção científica em base (banco) de dados, tendo como predominante as produções em TCC (28\%). Inferimos que base de dados pode ser considerada uma área consolidada, com muitos trabalhos produzidos, inclusive com um livro publicado. Quanto as menores produções, a tabela quatro (4) apresenta as opções livros, projetos de pesquisa, outros e tese com apenas 1\% cada uma. 


\begin{tabular}{l|c|c}
\hline \multicolumn{1}{c|}{ Tipos de registro } & Produção & Porcentagem \\
\hline TCC & 13 & $28 \%$ \\
\hline Artigos & 12 & $26 \%$ \\
\hline Anais de congressos & 12 & $26 \%$ \\
\hline Dissertação & 03 & $06 \%$ \\
\hline Capítulos de Livros & 03 & $06 \%$ \\
\hline Livros & 01 & $02 \%$ \\
\hline Projetos de pesquisa & 01 & $02 \%$ \\
\hline Outras & 01 & $02 \%$ \\
\hline Tese TOTAL & 01 & $02 \%$ \\
\hline \multicolumn{2}{c|}{ TOy } \\
\hline
\end{tabular}

Tabela 4 - Tipos de registro da produção científica em bases (banco) de dados

Quanto aos tipos de produção em biblioteca digital, conforme a tabela cinco (5), novamente destacaram-se os TCC com 35\% dos materiais produzidos. Depreende-se que os trabalhos de pós-graduação geralmente não são continuações de produções realizadas nos TCC ao verificarmos possíveis relações entre os tipos supracitados. No que se refere as menores quantidades de produções, com apenas $2 \%$ cada, temos a dissertação e os projetos de pesquisa.

\begin{tabular}{|c|c|c|}
\hline Típos de registro & Produção & Porcentagem \\
\hline TCC & 15 & $35 \%$ \\
\hline Artigos & 12 & $29 \%$ \\
\hline Anais de congressos & 04 & $10 \%$ \\
\hline Outros & 04 & $10 \%$ \\
\hline Capítulos de Livros & 03 & $07 \%$ \\
\hline Resumos expandidos & 02 & $05 \%$ \\
\hline Dissertação & 01 & $02 \%$ \\
\hline Projetos de pesquisa & 01 & $02 \%$ \\
\hline TOTAL & 42 & $100 \%$ \\
\hline
\end{tabular}

Tabela 5 - Tipos de registro da produção científica em biblioteca digital

A questão seis envolveu os tipos de registros da produção científica em repositório digital. Conforme pode ser observado na tabela seis (6), a área em questão encontra-se mais representativa em anais de congresso (35\%) dos documentos produzidos. Entretanto, apenas 3\% representa a produção de livros e repositórios digitais. No total, inferimos que muitas instituições estão preocupadas em montar seus repositórios institucionais e assim tal necessidade acaba provocando o aparecimento de produções/documentos nessa área.

\begin{tabular}{l|c|c}
\hline \multicolumn{1}{c|}{ Tipos de registro } & Produção & Porcentagem \\
\hline Anais de congressos & 13 & $35 \%$ \\
\hline Outros & 08 & $21 \%$ \\
\hline TCC & 07 & $18 \%$ \\
\hline Artigos & 05 & $13 \%$ \\
\hline Capítulos de Livros & 02 & $05 \%$ \\
\hline Projetos de pesquisa & 02 & $05 \%$ \\
\hline Livros TOTAL & 01 & $03 \%$ \\
\hline \multicolumn{2}{c|}{ T8 } & $\mathbf{1 0 0 \%}$ \\
\hline
\end{tabular}

Tabela 6 - Tipos de registro da produção científica em repositório digital

Também almejamos descobrir os tipos de registro da produção na área de revistas eletrônicas. A tabela sete (7) mostra-nos que foram identificados nove trabalhos no formato de anais de congressos, representando $34 \%$ do total. Entretanto, apenas 4\% representam produções em tese. 


\begin{tabular}{l|c|c}
\multicolumn{1}{c|}{ Tipos de registro } & Produção & Porcentagem \\
\hline Anais de congressos & 09 & $34 \%$ \\
\hline Livros & 05 & $19 \%$ \\
\hline TCC & 05 & $19 \%$ \\
\hline Artigos & 02 & $08 \%$ \\
\hline Capítulos de Livros & 02 & $08 \%$ \\
\hline Outros & 02 & $08 \%$ \\
\hline Tese & 01 & $04 \%$ \\
\hline \multicolumn{1}{c|}{ TOTAL } & $\mathbf{2 6}$ & $\mathbf{1 0 0} \%$ \\
\hline
\end{tabular}

Tabela 7 - tipos de registro da produção científica em revista Eletrônica

Apesar do assunto revista eletrônica ser um tema importante para a profissão, especialmente no que se refere à OAI, tendo como principal campo de atuação os periódicos que utilizam o SEER, infere-se uma área de produção pouco expressiva. Foi possível também perceber que existem produções, na temática em questão, oriundos de professores de outras áreas da biblioteconomia, como gestão e serviços de informação.

A questão de número oito objetivou descobrir os tipos de registro da produção em metadados, identificando apenas um artigo e um TCC sobre o assunto, quantidade pequena mesmo a área de metadados ser de preocupação dos bibliotecários por auxiliar na descrição de dados. Eles são pré-requisitos para implementação de SAB, além de serem aplicados em bibliotecas e repositórios digitais, já que lidam com a representação da informação.

\begin{tabular}{|c|c|c|}
\hline Tipos de registro & Produção & Porcentagem \\
\hline Artigos & 01 & $50 \%$ \\
\hline TCC & 01 & $50 \%$ \\
\hline TOTAL & 02 & $100 \%$ \\
\hline
\end{tabular}

Tabela 8 - Tipos de registro da produção científica em metadados

A nona questão abordou os tipos de produção científica em SAB e, surpreendentemente, este foi um dos temas que recebeu a menor quantidade de trabalhos produzidos de acordo com o levantamento, ou seja, com apenas sete produções. O tipo de registro que mais tratou desse assunto foi o TCC (44\%). Um incentivo de que este panorama possa mudar os valores encontrados refere-se a inserção de recursos da Web 2.0 em SAB diante do atual perfil e necessidades dos usuários, temática encontrada em TCC do curso de biblioteconomia da UnB, opondo-se aos artigos, dissertação, projetos de pesquisa e tese com 14\% cada um.

\begin{tabular}{l|c|c}
\hline \multicolumn{1}{c|}{ Tipos de registro } & Produção & Porcentagem \\
\hline TCC & 03 & $44 \%$ \\
\hline Artigos & 01 & $14 \%$ \\
\hline Dissertação & 01 & $14 \%$ \\
\hline Projetos de pesquisa & 01 & $14 \%$ \\
\hline Tese TOTAL & 01 & $14 \%$ \\
\hline \multicolumn{2}{c|}{ TOT } & $\mathbf{1 0 0 \%}$ \\
\hline
\end{tabular}

Tabela 9 - Tipos de registro da produção científica em SAB

Na décima questão o enfoque foi dado aos tipos de registro da produção em Web. Conforme a tabela nove (9), a quantidade de produções em anais representa $32 \%$ do total dos documentos produzidos em Web, diferentemente da pequena produção em livros e teses com 3\% para cada uma destas duas últimas opções citadas. 


\begin{tabular}{|c|c|c|}
\hline Tipos de registro & Produção & Porcentagem \\
\hline Anais de congressos & 09 & $32 \%$ \\
\hline Artigos & 06 & $21 \%$ \\
\hline Dissertação & 05 & $17 \%$ \\
\hline TCC & 03 & $10 \%$ \\
\hline Projetos de pesquisa & 02 & $07 \%$ \\
\hline Outros & 02 & $07 \%$ \\
\hline Livros & 01 & $03 \%$ \\
\hline Tese & 01 & $03 \%$ \\
\hline TOTAL & 29 & $100 \%$ \\
\hline
\end{tabular}

Tabela 10 - Tipos de registro da produção científica em Web

Ao compararmos a utilização dos recursos da Web, a produção deixa a desejar. Ao longo da pesquisa foram identificados trabalhos que falavam da Internet, no entanto, sem existir especificação da geração envolvida. Não basta somente falar da Internet, dos recursos da Web, para ser considerado um trabalho de TI, isto é, se faz necessário abordar recursos, aplicações, protocolos e linguagens.

Ainda no tema Web a pesquisa analisou os tipos de registro da produção conforme suas gerações. Iniciando pela Web 1.0, apenas uma publicação foi identificada, nesse caso, um trabalho sobre taxonomia. A Web 1.0 é limitada, possuindo poucos (e/ou quase nenhum) recursos de interação e colaboração, provavelmente explicando a pequena produção na área. As bibliotecas conseguiram se inserir na Internet, de forma mais intensa, a partir da Web 2.0. Nesta última geração citada, de acordo com o contexto de interação entre ferramentas e os usuários, é justificável que seja o assunto dentro da área de Web que se destaca em comparação às outras fases. Utilizando recursos para facilitar e agilizar a colaboração dos usuários e fornecendo serviços e produtos de acordo com o perfil de cada usuário, a Web 2.0 se torna assunto bastante abordado pelos profissionais da informação, em especial pelo grupo estudado nessa pesquisa. Os tipos de registros mais utilizados para produção deste conteúdo são os anais de congresso $(36 \%)$, artigos $(17 \%)$ e dissertação (17\%), representados por 23 materiais. Ainda na questão Web, como área em crescimento, a terceira geração nos apresentou poucas produções, dentre as quais se destacam os artigos $(40 \%)$, anais $(20 \%)$, dissertação $(20 \%)$ e tese $(20 \%)$, no total de cinco registros. A Web 3.0 aparece em 2000 por iniciativa de Berners-Lee. Apesar de ser um assunto recente, ainda não é uma realidade consolidada nos ambientes digitais, especialmente nas bibliotecas. Essa geração, intitulada como "Web inteligente" ou "Web semântica", prevê maior capacidade de interpretação e personalização de conteúdo no ambiente digital.

\subsection{Outras áreas de Tl identificadas na pesquisa}

No decorrer da coleta de dados foram encontrados documentos que traziam outras áreas pertencentes à $\mathrm{TI}$, de forma a complementar a presente pesquisa, sendo seis campos representados pelo montante de 51 documentos. Sendo assim, a tabela 11 apresenta as outras áreas identificadas, mas que não faziam parte do escopo inicial quanto compreensão de TI adotada neste trabalho e respectivos valores de produção. Vale salientar que a opção tecnologias aplicadas corresponde aos temas introdutórios da área de Informática como o uso do pacote Microsoft Office, e-mails, blogs entre outros, e recursos de software usados na disciplina Editoração do curso de biblioteconomia da UnB. 


\begin{tabular}{l|c|c}
\multicolumn{1}{c|}{ Areas } & Produção & Porcentagem \\
\hline Arquitetura da informação (AI) & 19 & $30 \%$ \\
\hline Tecnologias aplicadas & 12 & $19 \%$ \\
\hline GED & 10 & $16 \%$ \\
\hline Indexação automática & 05 & $08 \%$ \\
\hline $\begin{array}{l}\text { Sistema de (recuperação) } \\
\text { informação }\end{array}$ & 04 & $06 \%$ \\
\hline Segurança da informação & 04 & $06 \%$ \\
\hline Preservação digital & 03 & $05 \%$ \\
\hline Acessibilidade & 03 & $05 \%$ \\
\hline Usabilidade & 02 & $03 \%$ \\
\hline Computação em nuvem & 01 & $02 \%$ \\
\hline \multicolumn{1}{c|}{ TOTAL } & 51 & $100 \%$ \\
\hline
\end{tabular}

Tabela 11 - Outras áreas de TI identificadas na pesquisa

A área de Al foi a que se destacou com $30 \%$ do total, trazendo consigo estudos que objetivam o desenvolvimento de interfaces em ambientes digitais por meio de debates sobre representação, organização, navegação e busca. Esta é uma temática relevante para o bibliotecário, pois a sua atuação transcendeu o ambiente físico frente a participação na construção dos ambientes digitais, na tentativa de garantir as melhores estratégias para o tratamento e organização da informação e, assim, oferecer uma recuperação satisfatória ao usuário. Destacam-se os temas preservação digital e computação nas nuvens, áreas que vêm ganhando espaço nas discussões da biblioteconomia, pois a preocupação não se limita mais unicamente ao acesso, mas a longevidade de determinado suporte e como este será armazenado, especialmente em uma produção cada vez maior e de recuperação de informação em ambientes digitais, como é o caso das bibliotecas e repositórios digitais. No caso dos destaques supracitados, os valores correspondentes a preservação digital (5\%) e computação nas nuvens $(2 \%)$ refletem assuntos relativamente recentes e que apresentam um panorama de crescente quantidade de produções.

\section{Conclusões}

A TI pode ser considerada uma área responsável por desenvolver tecnologias digitais aplicadas nos variados setores da sociedade por meio de recursos de hardwares e softwares, como a automação de processos, contexto em que nos traz a biblioteca digital, por exemplo, área que pode ser considerada uma área de TI, já que é criada, mantida e acessada/utilizada no meio digital.

A mensuração da produção científica nesta área de estudo foi importante para a apresentação de um panorama sobre a geração de documentos em determinados assuntos de TI em biblioteconomia. Com base na proposta inicial, foi possível concluir que as áreas de Bases de dados, biblioteca digital e repositório demonstram representativas contribuições por parte dos docentes de biblioteconomia que tiverem seus currículos analisados. São assuntos em evidência, visto o crescimento de fontes eletrônicas e outros tipos de documentos que demandam tratamento especial para uma recuperação eficaz. No entanto, os SAB e metadados não apresentaram uma quantidade de produção representativa se comparado com outras áreas.

Compreendemos que o profissional da informação deverá conhecer/usar ferramentas e participar do processo de desenvolvimento de sistemas, informando os pré-requisitos necessários para tal, tanto na perspectiva tecnológica (metadados, por exemplo), quanto na visão biblioteconômica (campos de catalogação, por exemplo). Por isso justifica-se as áreas, aqui de menor expressão, serem tão importantes para os profissionais da informação, especialmente pelos adventos tecnológicos que surgem constantemente. Mesmo a área de SAB nos inferir ser ultrapassada, segundo os dados dos pesquisados, aspectos como cooperação, recursos interativos e colaboração social de informação, da Web 2.0, fazem com que esta temática seja reinventada.

Durante a coleta de dados deparamo-nos também com a descoberta de outros assuntos de TI, ocorrência que nos motivou a apresentar a produção científica destes outros temas, tendo maiores produções em anais de congresso, TCC e artigos de periódicos respectivamente: Al, tecnologias aplicadas, GED, indexação automática, sistema de (recuperação) da informação, segurança da informação, preservação digital, acessibilidade, usabilidade e computação em nuvem. 
Os resultados apresentados podem contribuir para o atual momento que vive o curso de biblioteconomia da UnB, ou seja, passando pelo momento de estudos sobre a reformulação do plano político pedagógico (PPP) e, consequentemente, promovendo a reformulação de conteúdos programáticos, além da oferta de novas disciplinas e turmas (optativas) como seminários em TI nas perspectivas de Al e bibliotecas digitais, ao passo que estudos futuros devem ser realizados, especialmente pela dinamicidade da $\mathrm{Tl}$ e exigências referentes às atualizações curriculares.

Depreende-se também que existe por parte dos alunos interesse em temas de TI, conclusão realizada por meio da observação da quantidade de TCC produzidos, especialmente em base de dados e bibliotecas digitais. No entanto poucos dão continuidade à exploração dos assuntos e/ou tem interesse em pesquisas nas áreas de $\mathrm{TI}$ desenvolvidas na graduação, o que foi possível comprovar por meio da pequena quantidade de dissertações e teses nesta temática.

Assim conclui-se que a análise da produção científica auxilia na tomada de decisão, idealiza um panorama de pesquisa dos professores, ajuda a compreender como determinada área se comporta e sua principal composição de assuntos.

\section{Referências}

ALECRIM, E. O que é Tecnologia da Informação (TI)? InfoWester: hardware, 2011. Disponível em: $<$ http://www.infowester.com/ti.php>. Acesso em: 11 dez. de 2013.

ANDRADE, I. A. [et al.]. Inteligência coletiva e ferramentas web 2.0: a busca da gestão da informação e do conhecimento em organizações. Perspectivas em Gestão \& Conhecimento, João Pessoa, v. 1, n. especial, p. 27-43, out. 2011. Disponível em: $<$ http://periodicos.ufpb.br/ojs/index.php/pgc/article/view/10385/6101>. Acesso em: 25 ago. 2013.

BRASIL. CONSELHO NACIONAL DE DESENVOLVIMENTO CIENTÍFICO E TECNOLÓGICO (CNPQ). Sobre a plataforma Lattes. 2013. Disponível em < http://lattes.cnpq.br/>. Acesso em: 04 fev. 2013.

BRASIL. INSTITUTO BRASILEIRO DE CIÊNCIA E TECNOLOGIA (IBICT). OJS em uma hora: introdução ao Sistema Eletrônico de Editoração de Revistas SEER/OJS. Brasília: IBICT, 2006. 144 p. Disponível em: $<$ http://seer.ibict.br/images/stories/file/manuais/ojs uma hora.pdf>. Acesso em: 11 dez. 2013.

BUENO, W. C. Comunicação científica e divulgação científica: aproximações e rupturas conceituais. Informação \& Informação, Londrina, v. 15, n. esp., p. 1-12, 2010. Disponível em: <http://www.uel.br/revistas/uel/index.php/informacao/article/view/6585/6761>. Acesso em: 20 out. 2014.

CUNHA, M. B. Bases de dados no Brasil: um potencial inexplorado. Ciência da Informação, Brasília, v. 18 (1), p. 45-47, jan./jun. 1989. Disponível em <www.brapci.ufpr.br/download.php?dd0=9527>. Acesso em: 11 dez. 2013.

CUNHA, M. B. Das bibliotecas convencionais às digitais: diferenças e convergências. Perspectivas em Ciência da Informação, Belo Horizonte, v. 13, n. 1, p. 2-17, jan./abr. 2008. Disponível em: $<$ http://www.scielo.br/scielo.php?script=sci arttext\&pid=S1413-99362008000100002>. Acesso em: 20 nov. 2014.

CUNHA, M. B.; CAVALCANTI, C. R. O. Dicionário de biblioteconomia e arquivologia. Brasília: Briquet de Lemos; Livros, 2008. $451 \mathrm{p}$.

DA SILVA, M. B.; DIAS, G. A. O sistema de automação em bibliotecas OpenBiblio aplicado à disciplina automação em bibliotecas. Biblionline, João Pessoa, v. 6, n. 1, p. 53-71, 2010. Disponível em: <http://www.biblionline.ufpb.br/ojs2/index.php/biblio/article/view/4903/3708>. Acesso em: 10 dez 2013.

DA SILVA, M. B. Interfaces e formatos de intercâmbio de informação na Internet: Web 1.0 (top-down). Brasília: Faculdade de Ciência da Informação, UnB, 2013a. (Material didático).

DA SILVA, M. B. Interfaces e formatos de intercâmbio de informação na Internet: Web 2.0 (bottom-up). Brasília: Faculdade de Ciência da Informação, UnB, 2013b. (Material didático).

DA SILVA, M. B. Metadados: conceitos, recursos, tipos, usos/necessidades e esquemas. Brasília: Faculdade de Ciência da Informação, UnB, 2013. (Material didático).

FERREIRA, S. M. P.; MODESTO, F.; WEITZEL, S. R. Comunicação científica e o protocolo OAl: uma proposta na área das Ciências da Comunicação. Comunicação \& Sociedade, Braga, v. 6, p. 193-209, 2004. Disponível em: <http://www.lasics.uminho.pt/ojs/index.php/comsoc/article/view/1235/1178>. Acesso em: 11 dez. 2013.

LEITE, F. C. L. Como gerenciar e ampliar a visibilidade da informação científica brasileira: repositórios institucionais de acesso aberto. Brasília: IBICT, 2009. 120 p. 
LIRA JÚNIOR, M. A. Sistema Lattes do CNPq. 1999. Disponível em: <http://lira.pro.br/wordpress/wpcontent/uploads/2009/08/Sistema-Lattes-do-CNPq.pps>. Acesso em: 11 dez 2013.

MARCONI, M. A.; LAKATOS, E. M. Fundamentos de metodologia científica. 6. ed. São Paulo: Atlas, 2007. 315 p.

MÁRDERO ARELLANO, M. A.; SANTOS, R.; FONSECA, R. SEER: disseminação de um sistema eletrônico para editoração de revistas científicas no Brasil. Arquivística.net, Rio de Janeiro, v. 1, n. 2, p. 75-82, jul./dez. 2005. Disponível em: <http://eprints.rclis.org/17598/1/Miguel Regina-Ramon.pdf>. Acesso em: 20 nov. 2014

MEADOWS, Arthur Jack. A comunicação científica. Brasília: Briquet de Lemos Livros, 1999.

MERLO, T. R. Epistemologia do Conhecimento e ciência da informação: uma retomada histórica com foco no papel da universidade geração de conhecimento na sociedade da informação. 2006. Disponível em: $<$ http://www.kmol.online.pt/teses/mer06.pdf>. Acesso em: 02 set. 2013.

MUELLER, S. P. M. O periódico científico. In: CAMPELLO, B. S.; CENDÓN, B. V.; KREMER, J. M. (Org.). Fontes de informação para pesquisadores e profissionais. Belo Horizonte: Editora UFMG, 2000. p. 73-95

NORONHA, D. P.; KIYOTANI, N. M.; JUANES, I. A. S. Produção científica de docentes da área de comunicação. Informação e Sociedade, João Pessoa, v. 13, n. 1, p. 139-157, jan./jun. 2003. Disponível em: $<$ <htp://www.ies.ufpb.br/ojs/index.php/ies/article/view/124/1579>. Acesso: em 20 set. 2014.

O'REILLY, T. What Is Web 2.0: design patterns and business models for the next generation of software. 2005. Disponível em <http://www.oreillynet.com/pub/a/oreilly/tim/news/2005/09/30/what-is-web-20.html> Acesso em: 20 nov. 2014.

PERUCCHI, V.; ARAÚJO JÚNIOR, R. Produção científica sobre inteligência competitiva da Faculdade de Ciência da Informação da Universidade de Brasília. Perspectivas em Ciência da Informação, Belo Horizonte, v. 17, n. 2, p. 37-56, abr./jun. 2012. Disponível em:

$<$ http://repositorio.unb.br/bitstream/10482/11670/1/ARTIGO ProducaoCientificalnteligencia\%20Competitiva.pdf>. Acesso em 12 nov. 2013.

PRICE, D. J. S. Desenvolvimento da ciência: análise histórica, filosófica, sociológica e econômica (o). Rio de janeiro: Livros Técnicos e Científicos, 1976. 77 p.

PRODANOV, C. C. Metodologia do trabalho científico: métodos e técnicas da pesquisa e do trabalho acadêmico. 2. ed. Novo Hamburgo: Universidade Feevale, 2013. 276 p.

RAMALHO, R. A. S.; VIDOTTI, S. A. B. G.; FUJITA, M. S. L. Web semântica: uma investigação sob o olhar da Ciência da Informação, DataGramaZero, Rio de Janeiro, v. 8, n. 6, dez. 2007. Disponível em: <http://www.dgz.org.br/dez07/Art 04.htm>. Acesso em: 10 dez. 2014.

REZENDE, A. P. Centro de informação jurídica eletrônico e virtual. Ciência da Informação, Brasília, v. 29, n. 1, p. 51-60, jan./abr. 2000. Disponível em: <http://www.scielo.br/pdf/ci/v29n1/v29n1a6.pdf>. Acesso em: 30 nov. 2014

ROWLEY, J. A biblioteca eletrônica. 2. ed. Brasília: Briquet de Lemos/Livros, 2002. 399 p.

SABINO, J. Web 3.0 e Web semântica: do que se trata? 2007. 3 p. Disponível em <http://www.cin.ufpe.br/ hsp/Microsoftweb.pdf>. Acesso em: $10 \mathrm{dez} .2014$.

SANTOS, R. N. M. Produção científica: por que medir? O que medir? Revista digital de Biblioteconomia e Ciência da Informação, Campinas, v.1, n. 1, p.22-38, jul./dez., 2003. Disponível em: <http://eprints.rclis.org/6264/1/RDBCl-03.pdf>. Acesso em: 20 mar. 2014.

SILVA, M. F. F. A visibilidade das bibliotecas públicas na web: acesso e disponibilidade de informação. $42 \mathrm{f}$. Trabalho de conclusão de curso (Graduação) - Curso de Biblioteconomia, Universidade Federal da Paraíba, João Pessoa, 2011.

SOUZA, M. I. F.; VENDRUSCULO, L. G.; MELO, G. C. Metadados para a descrição de recursos de informação eletrônica: utilização do padrão Dublin Core. Ciência da Informação, Brasília, v. 29, n. 1, p. 93-102, jan./abr. 2000. Disponível em: $<$ http://www.scielo.br/pdf/ci/v29n1/v29n1a10.pdf >. Acesso em: 30 dez. 2013.

SOUZA, T. B.; CATARINO, M. E.; SANTOS, P. C. dos. Metadados: catalogando dados na internet. Transinformação, Campinas, v. 9, n. 2, p. 93-105, maio/ago., 1997. Disponível em: $<$ http://200.18.252.94/seer/index.php/transinfo/article/viewFile/1586/1558>. Acesso em 30 dez. 2013.

STALLMAN, R. The GNU Operating System and the Free Software Movement. In: DiBONA, C.; OCKMAN, S.; STONE, M. Open Sources: voices of the Open Source Revolution. Sebastopol: O’Reilly \& Associates, p. 53-70, 1999.

VALÉRIO, P. M. Comunicação científica e divulgação: o público na perspectiva da Internet. In: PINHEIRO, L. V. R.; OLIVEIRA, E. C. P. (Orgs.) Múltiplas facetas da comunicação e divulgação científicas: transformações em cinco séculos. Brasília: IBICT, 2012. p. 150-167 
VIANA, C. L. M.; MÁRDERO ARELLANO, M. A.; SHINTAKU, M. Repositórios institucionais em ciência e tecnologia: uma experiência de customizacão do DSpace, 2005. In: Simpósio Internacional de Bibliotecas Digitais, São Paulo, 28 nov. - 02 dez. 2005. Disponível em: <http://eprints. rclis.org/7168/1/viana358.pdf>. Acesso em: 12 ago. 2014.

VILAN FILHO, J. L. Introdução à base de dados. Brasília: Faculdade de Ciência da Informação, UnB, 2010. (Material didático).

WEITZEL, S. R. Fluxo da informação científica. In: POBLACIÓN, D. A.; WITTER, G. P.; SILVA, J. F. M. (Org.). Comunicação \& produção científica: contexto, indicadores e avaliação. São Paulo: Angellara, 2006, p. 81-114.

\section{Dados dos autores}

\section{Bruna Guedes Martins da Silva}

Graduada em Biblioteconomia. Universidade de Brasília.

brunagms1991@gmail.com

\section{Márcio Bezerra Da Silva}

Doutorando em Ciência da Informação pela Universidade Federal da Bahia (início 2012). Mestre em Ciência da Informação pela Universidade Federal da Paraíba (2011). Graduação em Biblioteconomia pela Universidade Federal da Paraíba (2006). Tecnólogo em Processamento de Dados pela Escola Técnica Virgínia Patrick-RJ (1996). Professor da Faculdade de Ciência da Informação (FCl) da Universidade de Brasília (UnB). Experiência e formação na área de Processamento de Dados (Computação). Atualmente se dedicando a direcionar e utilizar tal experiência na Educação (ensino), Ciência da Informação e áreas afins. Interesse por Tecnologias; Banco de Dados; Arquitetura da Informação, Acessibilidade, Usabilidade e Web; Representação, Organização e Recuperação da Informação. Membro dos grupos de estudos Leitura, Organização, Representação, Produção e Uso da Informação (LORPUI) - UFPB; G-Acervos manuscriptológicos, bibliográficos, iconográficos, etnográficos: organização, preservação e interfaces das tecnologias da informação e comunicação - UFBA; e Publicações Eletrônicas - UNB.

\section{marciobdsilva@unb.br}

$\begin{array}{ll}\text { Recibido-Received } & : 2015-05-02 \\ \text { Aceptado-Accepted } & : 2015-06-29\end{array}$

\footnotetext{
${ }^{1}$ Link: http://enancib.ibict.br/index.php/enancib/index

${ }^{2}$ Link: http://www.cnpq.br/web/guest/pibic

${ }^{3}$ Link: http://www.scielo.org/php/index.php

${ }^{4}$ Link: http://repositorio.unb.br/

5 Link: http://seer.bce.unb.br/index.php/RICI/index

${ }^{6}$ Link: http://www.pergamum.pucpr.br/redepergamum/

${ }^{7}$ Link: http://biblivre.org.br/

${ }^{8}$ Acrônomo da frase: What-You-See-Is-What-You-Get.

${ }^{9}$ Link: http://www.oreilly.com/

${ }^{10}$ Link: http://semanticweb.org/wiki/FOAF

${ }^{11}$ Link: http://lattes.cnpq.br/

${ }^{12}$ Link: http://www.capes.gov.br/

${ }^{13}$ Demais tipos de produção técnica: prefácio de livros, editoração de publicações/materiais/apostilas e cursos ministrados.
}

\section{$(c c)$ BY}

This work is licensed under a Creative Commons Attribution 4.0 United States License.

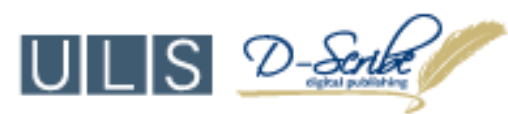

This journal is published by the University Library System of the University of Pittsburgh as part of its D-Scribe Digital Publishing Program and is cosponsored by the University of Pittsburgh Press. 